\title{
Radiation induces primary osteocyte senescence phenotype and affects osteoclastogenesis in vitro
}

\author{
YUYANG WANG, LINSHAN XU, JIANPING WANG, JIANGTAO BAI, JIANGLONG ZHAI and GUOYING ZHU \\ Department of Radiation Protection, Institute of Radiation Medicine, Fudan University, Shanghai 200032, P.R. China
}

Received August 28, 2020; Accepted February 10, 2021

DOI: $10.3892 / \mathrm{ijmm} .2021 .4909$

\begin{abstract}
Irradiation-induced bone remodeling imbalances arise as a consequence of the dysregulation of bone formation and resorption. Due to the abundance of osteocytes, their long life and their dual-regulatory effects on both osteoblast and osteoclast function, they serve as critical coordinators of bone remolding. In the present study, femur and tibia-derived primary osteocytes were cultured and irradiated to observe the functional changes and the cellular senescence phenotype in vitro. Irradiation directly reduced cell viability, affected the crucial dendritic morphology and altered the expression of functional proteins, including upregulation of receptor activator of nuclear factor- $\kappa \mathrm{B}$ ligand and sclerostin, and downregulation of osteoprotegerin. Irradiated osteocytes were shown to exhibit notable DNA damage, which resulted in the initiation of a typical cellular senescence phenotype. Furthermore, it was found that irradiation-induced prematurely senescent osteocytes stimulate molecular secretion, referred to as senescence-associated secretory phenotype (SASP), which may be involved in modulation of the bone microenvironment, including the promotion of osteoclastogenesis. Taken together, the results showed that irradiation triggered osteocyte senescence and the acquisition of an associated secretory phenotype. This further resulted in an imbalance of bone remodeling through senescent influence on proliferation, morphology and marker protein production, but also indirectly via a paracrine pathway through SASP secretion. The results of the present study may highlight the potential of SASP-targeted interventions for the management of radiation-induced bone loss.
\end{abstract}

\section{Introduction}

Radiotherapy, which has been used to treat malignant tumors for over a century, is still the most commonly used technique

Correspondence to: Mrs. Guoying Zhu, Department of Radiation Protection, Institute of Radiation Medicine, Fudan University, 2094 Xietu Road, Shanghai 200032, P.R. China

E-mail: zhugy@shmu.edu.cn

Key words: osteocyte, irradiation, cellular senescence, senescence-associated secretory phenotype, osteoclastogenesis clinically for the management of cancer (1). However, the efficacy of radiotherapy comes at the expense of damage to adjacent normal tissues, including tissues of the skeletal system (2-4). Irradiation initiates bone loss accompanied by bone fractures or even increases the risk of bone metastasis due to bone matrix degradation, which seriously impairs a patient's quality of life and is a major dose-limiting factor in the use of radiotherapy (5-7). Thus, further investigations to elucidate the mechanisms responsible for radiation-induced collateral damage of the skeleton should be performed. Osteocytes are the most abundant type of cells in the skeleton, are embedded within the mineralized bone matrix, and have long been deemed to be passive, metabolically inactive cells (8). However, studies have shown that osteocytes are multifunctional cells that both compose bone and respond to mechanical loads for weight support, and also exhibit key roles in bone remodeling and mineral homeostasis through secretory regulation of both osteoclasts and osteoblasts (9-12). Targeting osteocytes and osteocyte-mediated pathways may hold promise in treating irradiation-related bone damage, therefore it is essential to investigate the effects of irradiation on osteocytes, and the underlying mechanisms.

The characteristic dendrite-like morphology of osteocytes is determined by the expression of genes associated with dendritic formation and branching, such as E11/gp38, and dendrites are involved in the ability of osteocytes to communicate with other cells in the surrounding environment $(13,14)$. Existing research has shown E11 is involved in early osteocytogenesis and the formation of osteocyte dendrites (15). Sclerostin (SOST), a marker of mature osteocytes and a negative modulator of bone formation, is specifically secreted by osteocytes (16). Alternatively, osteocytes may generate a variety of functional pro-osteoclastogenic molecules, such as receptor activator of nuclear factor- $\kappa \mathrm{B}$ ligand (RANKL) or inhibitors, such as osteoprotegerin (OPG), to regulate bone resorption. As a major source of RANKL, osteocyte was also reported to release RANKL to the cell surface for stimulation with RANKL (17).

Radiation may result in notable DNA damage and place various stresses on cells, resulting in the initiation of typical cellular senescence, in which cells remain metabolically active, yet undergo irreversible cell cycle arrest and develop distinct phenotypic alterations, including chromatin organization, upregulation of p16, p21 and acquisition of a secretory phenotype $(5,18,19)$. Despite their maintained metabolic activity and 
resistance to apoptosis, which serve roles in preserving cellular integrity and function, dysfunctional intra- and extra-cellular effects in cellular senescence cannot be ignored. The dysfunctional secretion of pro-inflammatory cytokines, chemokines and matrix metalloproteinases, termed senescence-associated secretory phenotype (SASP), is a key feature of cellular senescence, and is considered a modulatory mechanism for surrounding cells (20). Previous research showed that radiation could generate senescent cells as well as the SASP in a chronic manner similar to aging, which influences fracture healing after radiation treatment. In addition, several factors derived from the accumulation of senescent cells are implicated as causal in age-related osteoporosis and imbalance of bone metabolism (21). Findings of previous studies of cellular senescence have primarily focused on stem cells $(22,23)$. By contrast, there are a limited number of studies on post-mitotic cells, such as the terminally differentiated osteocytes (24-26). Therefore, the biological functions and cellular senescence phenotypes regarding this type of bone cell should be explored to determine its relevance. Osteocytes can survive for decades within the bone matrix, making them one of the longest living cells in the body (9). However, the consequence of osteocyte senescence and its role in the pathophysiology of irradiation-related bone loss is poorly understood. Despite the existence of several cell lines that have been used to study osteocytes in vitro, the differences between primary osteocytes and the immortalized cell lines have not been studied, to the best of our knowledge. However, in vitro experiments, albeit important in the preliminary stages, cannot substitute for primary cells or in vivo models.

Taken together, osteocytes act as important orchestrators of bone remodeling, and may provide novel targets and strategies for intervention and treatment of related bone diseases, including cancer radiotherapy-induced bone loss. In the present study, the effect of $\gamma$-rays on the biological function of primary osteocytes was assessed. Subsequently, irradiation-induced senescence and its secretory phenotype were further explored, particularly regarding regulation of osteoclastogenesis through the corresponding SASP paracrine pathway. The results of the present study may provide a novel insight into the underlying mechanism, and highlight the clinical potential to manage cancer treatment-induced bone loss.

\section{Materials and methods}

Isolation of primary osteocytes. Primary osteocytes were isolated from 7-week-old male BALB/c mice (weight, $\sim 25 \mathrm{~g}$ ) purchased from the Department of Experimental Animals at Fudan University (Shanghai). All experimental procedures were approved by the Committee for Ethical Use of Experimental Animals at Fudan University (approval no. 2017-03-FYS-ZGY-01). A modified protocol of sequential collagenase/pancreatin digestion was utilized to isolate primary osteocytes (27-29). The femur and tibia of BALB/c male mice were aseptically dissected after sacrificing mice by cervical dislocation. The bones were placed in sterile PBS supplemented with $10 \%$ penicillin and streptomycin, followed by a series of digestion processes, as shown in Table I. Collagenase solution was prepared as $0.001 \mathrm{~g} / \mathrm{ml}$ collagenase type-I (Sigma-Aldrich; Merck KGaA) and $0.001 \mathrm{~g} / \mathrm{ml}$ collagenase type-II (Sigma-Aldrich; Merck KGaA) dissolved in PBS.
EDTA solution (5 mM; pH, 7.4) was prepared in magnesium and calcium-free PBS with $1 \%$ calf serum (Gibco; Thermo Fisher Scientific, Inc.). Trypsin (Gibco; Thermo Fisher Scientific, Inc.) was used directly, and all instruments were autoclaved in advance. Cell suspensions as well as the bone pieces were directly plated and cultured in $\alpha$-minimum essential medium ( $\alpha$-MEM; Gibco; Thermo Fisher Scientific, Inc.) supplemented with 5\% FBS (Gibco; Thermo Fisher Scientific, Inc.), 5\% calf serum and $1 \%$ penicillin/streptomycin (Sigma-Aldrich; Merck $\mathrm{KGaA}$ ). Cells were cultured at $37^{\circ} \mathrm{C}$ with $5 \% \mathrm{CO}_{2}$ in a humidified incubator for 7 days until cell confluency reached $>90 \%$.

Isolation of osteoblasts. Osteoblasts were isolated mechanically from calvaria of newborn BALB/c mice, purchased from the Department of Experimental Animals at Fudan University (Shanghai). All experimental procedures in mice were approved by the Committee for Ethical Use of Experimental Animals at Fudan University (approval no. 2017-03-FYS-ZGY-01). After carefully stripping off the periosteal layers and soft tissue on bone surface in PBS, the calvaria were then cut into 1-2 mm fragments. Subsequently, these bone pieces were digested with Trypsin solution for $20 \mathrm{~min}$ in an incubator, then pre-digested bone pieces were digested twice in collagenase type-II solution for $1 \mathrm{~h}$. Finally, the collagenase digestion was collected and centrifuged at $200 \mathrm{x} \mathrm{g}$ for $10 \mathrm{~min}$ at room temperature and the sediment osteoblasts were resuspended in $4 \mathrm{ml}$ DMEM (Gibco; Thermo Fisher Scientific, Inc.) supplemented with $10 \%$ fetal bovine serum (FBS; Gibco) and $1 \%$ penicillin/streptomycin for further culture.

Identification of primary osteocytes. Alkaline phosphatase (ALP) staining was used to identify primary osteocytes. ALP staining is weak in osteocytes obtained from long bones $(28,30)$. After removing the media, the cells were washed using PBS and then incubated with ALP staining solution for $2 \mathrm{~h}$ at room temperature, which was provided in a staining kit (Beyotime Biotechnology). Images of random fields of view were taken at x100 magnification using a light microscope (Leica Microsystems).

Expression levels of markers associated with osteocytes were also analyzed. Primary osteocyte lysates were obtained using RIPA lysis buffer (Beyotime Institute of Biotechnology), loaded on a $10 \%$ SDS-gel, resolved using SDS-PAGE and transferred to a PVDF membrane (EMD Millipore). After blocking with $5 \%$ skimmed milk in TBS supplemented with $0.1 \%$ Tween 20 (TBST) for $1 \mathrm{~h}$, the membrane was incubated with primary antibodies specific to E11 (cat. no. ab11936, Abcam; 1:1,000),P16 (cat. no. ab51243, Abcam; 1:1,000), P21 (cat. no. ab188224, Abcam; 1:1,000), RANKL (cat. no. ab45039, Abcam; 1:1,000), OPG (cat. no. ab183910, Abcam; 1:1,000), SOST (cat. no. ab63097, Abcam; 1:1,000) or $\beta$-actin (cat. no. 4970S, Cell Signaling Technology, Inc.; 1:10,000 at $4^{\circ} \mathrm{C}$ overnight. Subsequently, the membrane was washed three times with TBST, each for $10 \mathrm{~min}$, followed by incubation with an anti-mouse-IgG-HRP-conjugated or anti-rabbit-IgG-HRP-conjugated secondary antibody (cat. no. SA00001-2, Proteintech; 1:1,000) at room temperature for $1 \mathrm{~h}$. Signals were visualized using an ECL kit (Beyotime Institute of Biotechnology) and an Omega Lum ${ }^{\mathrm{TM}} \mathrm{C}$ Imaging System (Gel Company). Densitometry analysis was performed using Image J Software (NIH). 
Table I. Stepwise procedure for isolating osteocytes from mouse long bones.

\begin{tabular}{|c|c|}
\hline Step number & Step description \\
\hline 1 & $\begin{array}{l}\text { Soft tissue (adherent muscle and connective tissue) were cut off and the periosteum was scraped off using a } \\
\text { surgical blade. }\end{array}$ \\
\hline 2 & Epiphyses were cut off and the marrow was rinsed with PBS using a syringe. \\
\hline 3 & After extensive washing, bones were cut into 1-2 mm fragments in PBS. \\
\hline 4 & The remaining PBS was removed, and bone pieces were digested using trypsin solution for 20 min in an incubator. \\
\hline 5 & Bone pieces were digested with collagenase type-II solution at $37^{\circ} \mathrm{C}$ for $1 \mathrm{~h}$ in an incubator. \\
\hline 6 & Bone pieces were washed twice with PBS. \\
\hline 7 & $\begin{array}{l}\text { Bone pieces were incubated with EDTA solution at } 37^{\circ} \mathrm{C} \text { for } 30 \mathrm{~min} \text { in an incubator, and the EDTA solution was } \\
\text { collected. The bone pieces were once again rinsed in PBS, and the PBS was subsequently added to the EDTA } \\
\text { solution. }\end{array}$ \\
\hline 8 & $\begin{array}{l}\text { The mixed EDTA solution obtained in the step } 7 \text { was centrifuged at room temperature at } 200 \times \mathrm{g} \text { for } 10 \mathrm{~min} \text { and } \\
\text { the sedimented cells were resuspended in } 2 \mathrm{ml} \text { culture medium ( } \alpha \text { Minimum Essential Medium supplemented } \\
\text { with } 10 \% \text { FBS, calf serum and Pen/Strep). }\end{array}$ \\
\hline 9 & $\begin{array}{l}\text { Bone pieces were incubated with collagenase type-I solution at } 37^{\circ} \mathrm{C} \text { for } 30 \mathrm{~min} \text { in an incubator, and the } \\
\text { collagenase type-I solution was collected. The bone pieces were once again rinsed in PBS, and the PBS was } \\
\text { subsequently added to the collagenase solution. }\end{array}$ \\
\hline 10 & $\begin{array}{l}\text { The mixed collagenase solution obtained in step } 9 \text { was centrifuged at room temperature at } 200 \mathrm{x} \mathrm{g} \text { for } 10 \mathrm{~min} \text { and } \\
\text { the sediment cells were resuspended in } 2 \mathrm{ml} \text { culture medium. }\end{array}$ \\
\hline 11 & Step 7 was repeated. \\
\hline 12 & $\begin{array}{l}\text { The mixed solution obtained in step } 11 \text { was centrifuged at room temperature at } 200 \mathrm{x} \mathrm{g} \text { for } 10 \mathrm{~min} \text { and the } \\
\text { sedimented cells were resuspended in } 2 \mathrm{ml} \text { culture medium. }\end{array}$ \\
\hline 13 & Step 9 was repeated. \\
\hline 14 & $\begin{array}{l}\text { The mixed solution obtained in step } 13 \text { was centrifuged at } 200 \mathrm{x} \text { g for } 10 \mathrm{~min} \text { at room temperature and the } \\
\text { sedimented cells were resuspended in } 2 \mathrm{ml} \text { culture medium. }\end{array}$ \\
\hline 15 & $\begin{array}{l}\text { Sedimented cells in steps } 8,10,12 \text { and } 14 \text { were mixed and cultured together with digested bone pieces at } 37^{\circ} \mathrm{C} \\
\text { with } 5 \% \mathrm{CO}_{2} \text { in a humidified incubator for } 7 \text { days until cell confluency reached }>90 \% \text {. }\end{array}$ \\
\hline
\end{tabular}

Cell culture and irradiation treatment. Primary osteocytes were cultured as described above. For ionizing radiation, 1 day after cell plating, osteocytes were subjected to 2, 4, 6 or $8 \mathrm{~Gy}$ irradiation with ${ }^{137} \mathrm{Cs} \gamma$-rays (Nordion). The dose rate at the centre of the chamber was $66.7 \mathrm{cGy} / \mathrm{min}$, which was annually calibrated by the Shanghai Institute of Measurement and Testing Technology. $\mathrm{LiF}(\mathrm{Mg}, \mathrm{Cu}, \mathrm{P})$ thermoluminescent dosimeters were used to measure the actual radiation dose at different distances from the chamber centre $(31,32)$. Untreated cells ( 0 Gy) were used as the control. Subsequent analysis was performed 3 days after irradiation.

Irradiation-induced morphological and functional changes in osteocytes. The cell viability of irradiated osteocytes was detected using a Cell Counting Kit-8 assay (CCK8; Dojindo Molecular Technologies, Inc.). Briefly, osteocytes seeded in 96-well plates $\left(3 \times 10^{3}\right.$ cells/well) were subsequently treated with irradiation $(0,2,4$ or $8 \mathrm{~Gy})$, followed by incubation for 1 , 3 or 5 days. CCK 8 reagent was added at $10 \%$, and incubated for $2 \mathrm{~h}$ at $37^{\circ} \mathrm{C}$. The absorbance at $450 \mathrm{~nm}$ was examined using a microplate reader (Bioteck), and was considered to indicate cell viability.

The morphological changes including dendrite-like synapse and cytoskeleton in the irradiated osteocytes were examined by staining with tetramethyl rhodamine-phalloidin (Beijing Solarbio Science \& Technology Co., Ltd.) for F-actin and with DAPI (Dojindo Molecular Technologies, Inc.) for nuclei. Each staining step was processed at room temperature and incubated for $2 \mathrm{~h}$ in the dark. The number and dendritic length of osteocytes were quantitatively measured using SimplePCI software (HCImage, SimplePCI 6.6). Six random fields were chosen in three biological replicates, and representative images were captured using a Leica fluorescent microscope (Leica Microsystems, $\mathrm{GmbH}$ ) with a magnification of $\mathrm{x} 100$. The length of the dendrites was calculated by total length of dendrites/number of dendrites per cell.

Irradiation-induced osteocyte DNA damage. A total of $7 \mathrm{~h}$ after radiation treatment, osteocytes were fixed using $4 \%$ formaldehyde at room temperature for $20 \mathrm{~min}$. After washing with PBS, cells were permeabilized and blocked using $1 \%$ Triton X-100, 1\% BSA and 10\% FBS in PBS buffer for $1 \mathrm{~h}$ at room temperature, and then incubated with primary antibodies against $\gamma$-H2AX (cat. no. ab81299, Abcam; 1:250) overnight at $4^{\circ} \mathrm{C}$. Cells were washed with PBS twice and then incubated in the dark with anti-mouse-IgG-HRP-conjugated or anti-rabbit-IgG-HRP-conjugated secondary antibodies (cat. no. SA00001-2, Proteintech; 1:1,000) and DAPI (1:500; Beyotime Institute of Biotechnology) for $60 \mathrm{~min}$. The number of $\gamma$-H2AX foci was quantified using a laser confocal microscope (Zeiss LSM 880; Carl Zeiss AG) with a magnification of $x 60$. 
Irradiation-induced osteocyte senescence and its secretory phenotype. Senescence-associated $\beta$-galactosidase (SA- $\beta$-gal) expression was visualized using an SA- $\beta$-gal staining kit (Beyotime Institute of Biotechnology) according to the manufacturer's protocol. Cells were washed with PBS twice and fixed using a fixative solution at room temperature for $15 \mathrm{~min}$, and then stained with X-gal solution for $24 \mathrm{~h}$ at $37^{\circ} \mathrm{C}$ (without $\mathrm{CO}_{2}$ ). Cells were observed using a light microscope (Leica Microsystems, $\mathrm{GmbH}$ ) with a magnification of $\mathrm{x} 100$, and the percentage of SA- $\beta$-gal-positive cells in 10 random fields was calculated.

The levels of 40 different cytokines and chemokines in $700 \mu$ l supernatant of cultured osteocytes 3 days after irradiation were simultaneously detected using R\&D Systems Mouse Cytokine Array, Panel A (cat. no. ARY006; R\&D Systems, Inc.), according to the manufacturer's protocol. Signals were detected using chemiluminescence (Chemi Scope 6300) and subsequently quantitated with HLImage++ computer vision systems (1997, Western Vision Software).

Irradiation-induced senescent osteocyte-mediated osteoclastogenesis. Primary osteocytes were inoculated in a 24 -well plate $\left(4 \times 10^{3}\right.$ cells/well), cultured for $24 \mathrm{~h}$ and subsequently irradiated $(0,2,4$, and $8 \mathrm{~Gy})$. RAW264.7 cells $\left(2 \times 10^{3}\right.$ cells/well) were plated on top of the irradiated osteocytes and co-cultured in $\alpha$-MEM supplemented with $10 \%$ FBS and $25 \mathrm{ng} / \mathrm{ml}$ RANKL (PeproTech, Inc.). The induction medium was changed every 2 days. After 7 days, cells were fixed in $2.5 \%$ glutaraldehyde for $10 \mathrm{~min}$ at room temperature and stained for tartrate-resistant acid phosphatase (TRAP) activity using a TRAP staining kit according to the manufacturer's protocol (Sigma-Aldrich, Merck KGaA). TR AP-positive multinucleated cells with $>3$ nuclei were counted as osteoclasts and the area was analyzed using ImageJ.

Reverse transcription-quantitative PCR (RT-qPCR). Gene expression analysis was performed using RT-qPCR. Three days after irradiation, cells were washed with cold PBS three times and lysed using TRIzol ${ }^{\circledR}$ reagent (Invitrogen; Thermo Fisher Scientific, Inc.) to obtain total RNA. Reverse transcription was performed using a Quantscript RT kit (Tiangen Biotech) at $45^{\circ} \mathrm{C}$ for $15 \mathrm{~min}$ and $95^{\circ} \mathrm{C}$ for 3 min, and PCR was performed in an ABI QuantStudio 3 (Applied Biosystems; Thermo Fisher Scientific, Inc.) using PowerUp SYBR-Green MasterMix (Invitrogen; Thermo Fisher Scientific, Inc.) to a final volume of $10 \mu 1$. The thermocycling conditions used were: 40 cycles of $95^{\circ} \mathrm{C}$ for $15 \mathrm{sec}$ followed by $55^{\circ} \mathrm{C}$ for $15 \mathrm{sec}$ and $72^{\circ} \mathrm{C}$ for $1 \mathrm{~min}$. The primer sequences are listed in Table II. The relative mRNA expression levels of the indicated genes were quantified using the $2^{-\triangle \triangle C q}$ method (33). GAPDH was used as the loading control.

Statistical analysis. Data were analyzed by one-way ANOVA using SPSS 16.0 (SPSS, Inc.) and GraphPad Prism 5.0 (GraphPad Software, Inc.). Following each one-way ANOVA, Tukey's post hoc test was performed to compare all treatments against the control. Data are presented as the mean \pm standard deviation. $\mathrm{P}<0.05$ was considered to indicate a statistically significant difference.
Table II. Primer sequences for reverse transcription-quantitative PCR.

\begin{tabular}{ll}
\hline Genes & \multicolumn{1}{c}{ Sequence (5'-3') } \\
\hline$E 11$ & F: ACCGTGCCAGTGTTGTTCTG \\
& R: AGCACCTGTGGTTGTTATTTGT \\
$P 16$ & F: CGCAGGTTCTTGGTCACTGT \\
& R: TGTTCACGAAAGCCAGAGCG \\
$P 21$ & F: CCTGGTGATGCCGACCTG \\
& R: CCATGAGCGCATCGCAATC \\
$N F-\kappa B$ & F: TGCGATTCGCTATAAATGCG \\
$T N F-\alpha$ & R: ACAAGTTCATGTGGATGAGGC \\
& F: TCAGAATGAGGCTGGATAAG \\
$M M P 13$ & R: GGAGGCAACAAGGTAGAG \\
& F: CCTTGATGCCATTACCAGTCTC \\
$I L-1 \alpha$ & R: TCCACATGGTTGGGAAGTTCT \\
$I L-6$ & F: CTGAAGAAGAGACGGCTGAGT \\
& R: CTGGTAGGTGTAAGGTGCTGAT \\
GAPDH & F: ATGAACAACGATGATGCACTTG- \\
& R: GGTACTCCAGAAGACCAGAGG \\
& F: GGAGTCTACTGGTGTCTTC \\
& R: TCATCATACTTGGCAGGTT
\end{tabular}

MMP, matrix metalloproteinase; IL, interleukin; TNF- $\alpha$, tumor necrosis factor- $\alpha$.

\section{Results}

Identification of primary osteocytes. Osteocytes, traditionally viewed as a descendant of osteoblasts, exhibit distinct characteristics from osteoblasts $(30,34)$. In order to determine whether the isolated cells could reflect osteocyte metabolism traits in vitro, cellular dendrite-like synapse morphology, expression of ALP and expression levels of marker proteins were observed. Three days after isolation, digested primary osteocytes were present and were suspended in the medium, whereas on the 5th day, primary osteocytes emerged from the bone pieces, and cell populations obtained by direct digestion were observed. In the following culture process, it was noted that primary osteocytes proliferated continuously and presented a characteristic stellate shape with the formation of specific dendritic processes, characteristic to osteocytes, which are essential for osteocyte function (Fig. 1A).

In addition to the above morphological characteristics, osteocytes showed negative or only weak positive staining for ALP expression, whereas osteoblasts exhibited strong staining (Fig. 1B). Furthermore, primary osteocytes were confirmed by the expression of several marker proteins, including OPG, E11, RANKL, and SOST, which were produced almost exclusively in osteocytes (Fig. 1C). Overall, the process of isolation detailed in Table I was effectively used to obtain and identify primary osteocytes isolated from femur and tibia.

Irradiation reduces cell viability and directly disrupts fundamental biological functions. Taking into consideration the essential role of osteocytes in bone homeostasis, the fact that 
A

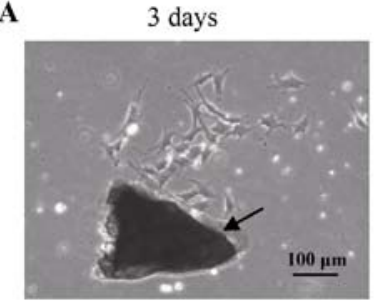

B

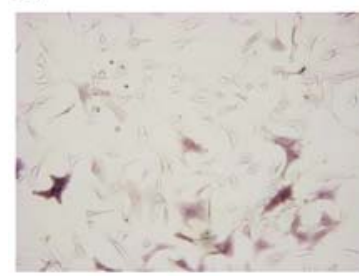

Osteocytes
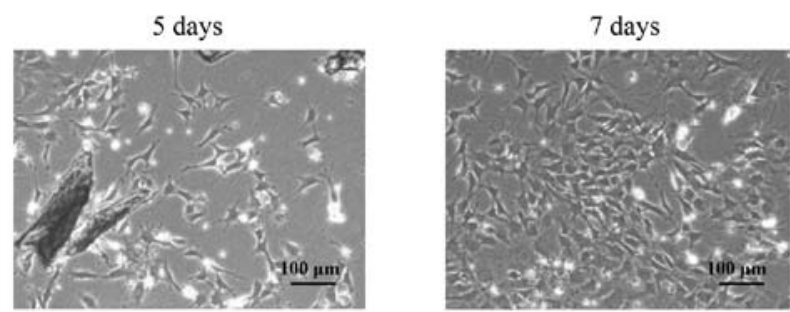

C

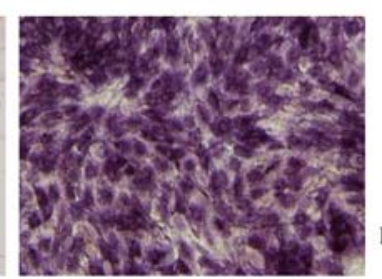

Osteoblasts

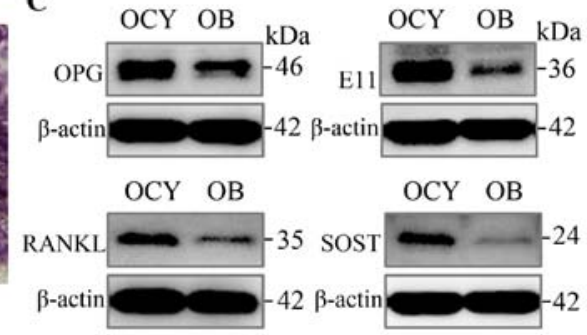

Figure 1. Proliferative primary osteocytes exhibit a typical morphology and characteristic marker protein expression. (A) Proliferation and characteristic morphology of primary osteocytes was observed using bright-field microscopy, 3,5 and 7 days after isolation. Bone pieces are indicated by the arrows. Scale bar, $100 \mu \mathrm{m}$. Magnification, x100. (B) ALP staining of primary osteocytes and osteoblasts, respectively. Scale bar, $100 \mu \mathrm{m}$. Magnification, x100. (C) Analysis of expression of the osteocyte markers, E11, SOST, RANKL and OPG in primary osteocytes using western blot analysis. ALP, alkaline phosphatase; SOST, sclerostin; RANKL, receptor activator of nuclear factor- $\mathrm{\kappa}$ ligand; OPG, osteoprotegerin.

A
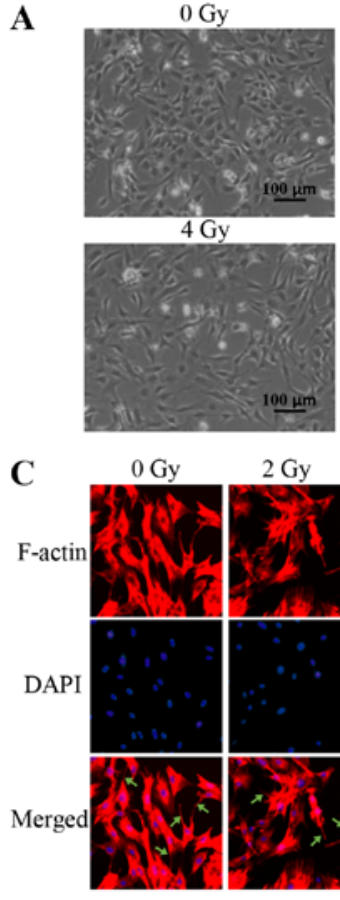

2 Gy
2 Gy
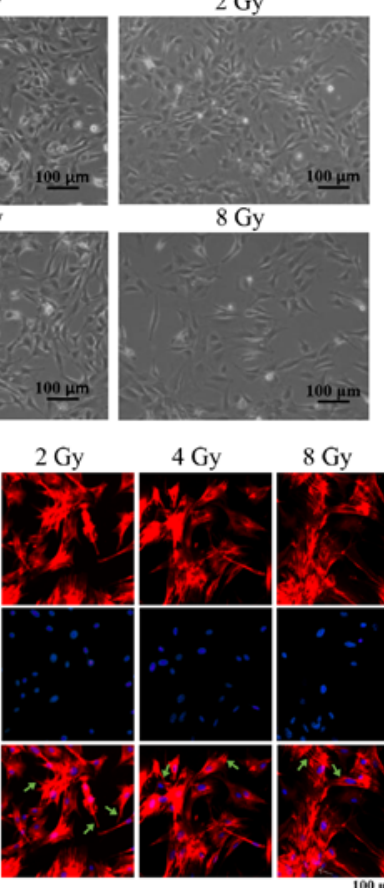

4 Gy

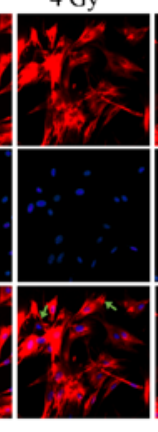

E11

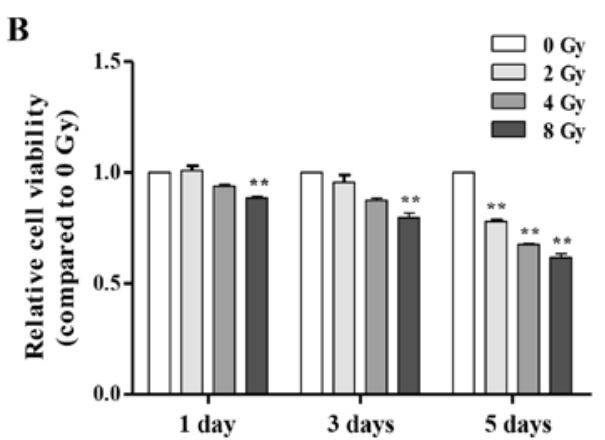

D

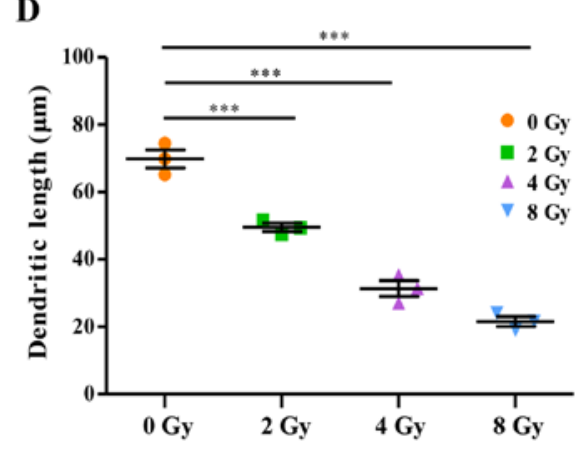

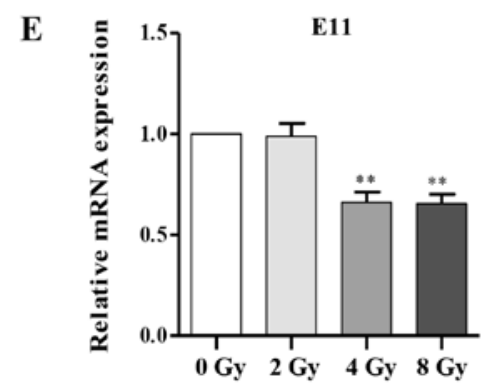

Figure 2. Irradiation disrupts cell viability and dendrite morphology. (A) Morphology and number of primary osteocyte was altered at 5 days after exposure to $\gamma$-rays. Scale bar, $100 \mu \mathrm{m}$. (B) Cell viability was quantitatively evaluated using a Cell Counting Kit- 8 assay (n=6). (C) F-actin and nuclei were stained for osteocyte cytoskeleton and typical dendrite-like synapse using phalloidin and DAPI fluorescence staining, respectively, 3 days after irradiation, and the typical dendrites are indicated by the green arrows. Scale bar, $100 \mu \mathrm{m}$. (D) Quantitative analysis of the change in dendritic length (n=6). (E) Relative mRNA expression levels of E11. Gene expression was normalized to $\beta$-actin and the control $(n=3)$. Expression was analyzed 3 days after irradiation. Data are presented as the mean \pm standard deviation. ${ }^{* *} \mathrm{P}<0.01,{ }^{* * *} \mathrm{P}<0.001$ vs. control. 
A
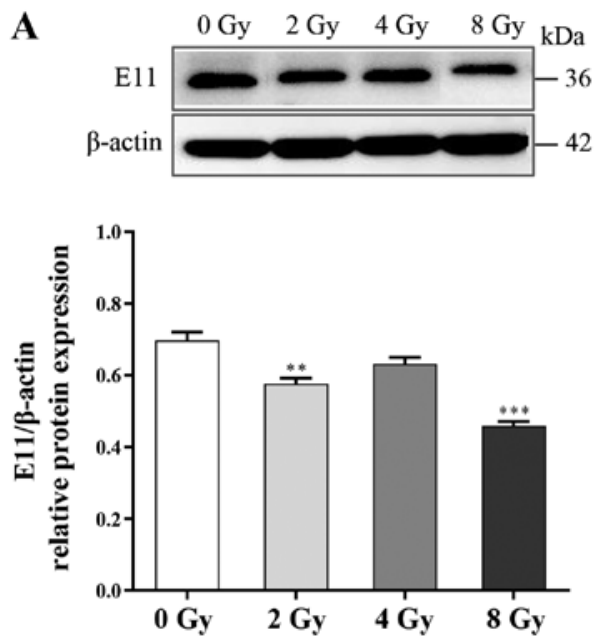

B
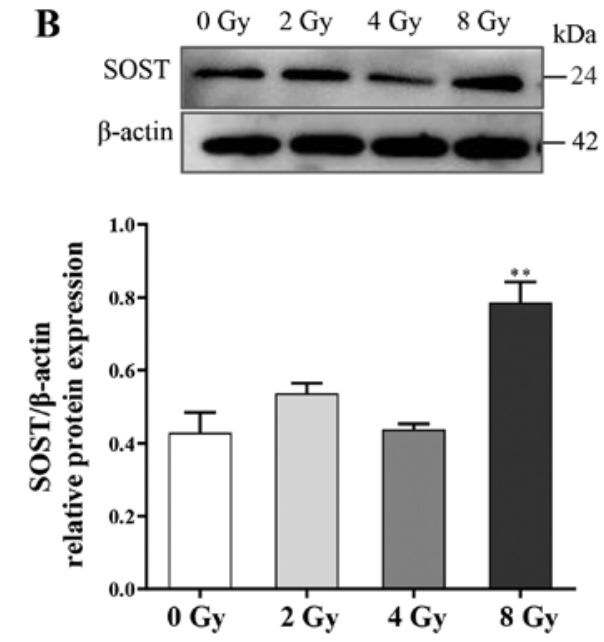

C

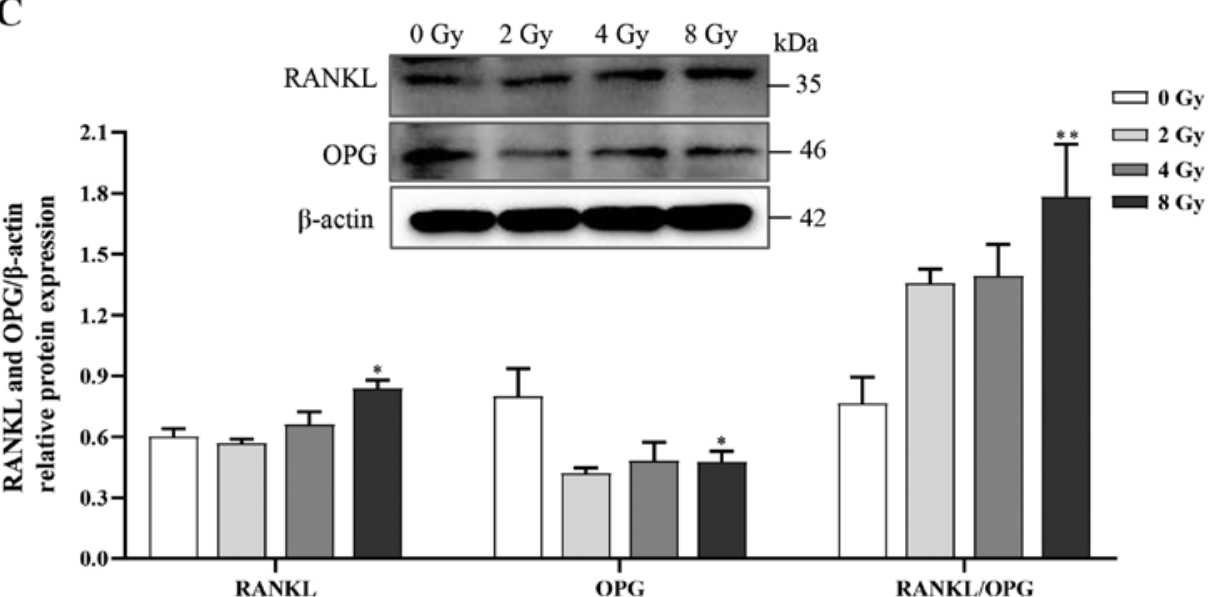

Figure 3. Irradiation affects expression of marker proteins in primary osteocytes. (A-C) Changes in expression of E11, SOST, RANKL, OPG and RANKL/OPG ratio in osteocytes 3 days after irradiation exposure were assessed by western blot analysis $(n=3)$. Data are presented as the mean \pm standard deviation. "P<0.05, ${ }^{* *} \mathrm{P}<0.01,{ }^{* * *} \mathrm{P}<0.001$ vs. control. SOST, sclerostin; RANKL, receptor activator of nuclear factor- $\kappa \mathrm{B}$ ligand; OPG, osteoprotegerin.

they account for $>90 \%$ of the composition of all bone cells and function in mechanical induction, a decreased number of osteocytes would result in bone loss (16). Viability and survival are therefore extremely important to ensure optimal function of the osteocyte network. Irradiation significantly affected the viability of primary osteocytes, which eventually resulted in a decreased number of osteocytes (Fig. 2A and B). Additionally, the multi-dendritic structure of osteocytes is a key feature closely associated with physiological function, including communication with other cells on the bone surface, and itself $(15,35)$. To determine whether irradiation influenced the dendritic morphology of primary osteocytes, cells were stained after irradiation for F-actin, and notable dose-dependent morphological alterations were observed including sparsely distributed cells, shortened or disappeared dendritic branches and disordered cytoskeleton compared with the control group (Fig. 2C and D). Accordingly, serving as an important marker in dendrite expansion, E11 mRNA expression was attenuated as the dose of irradiation was increased (Fig. 2E). Furthermore, to investigate the effects of irradiation on biological functions in osteocytes, changes in the expression of several regulatory factors, including E11, RANKL, OPG and SOST were examined. Following irradiation, the expression levels of E11 and OPG were attenuated, whereas the expression levels of both RANKL and SOST, which respectively activate bone resorption and inhibit bone formation, were significantly increased (Fig. 3). Thus, the unbalanced function of osteocytes could be the cellular basis for disturbances in bone remodeling following irradiation.

Irradiation induces DNA damage and cellular senescence. At the primary cell level, irradiation disrupted osteocyte viability and the expression of proteins associated with their biological functions. Focusing on the dysregulated intracellular molecular biology caused by irradiation and the underlying mechanism, it was shown that irradiation significantly promoted accumulation of $\gamma \mathrm{H} 2 \mathrm{AX}$ in osteocytes, a hallmark of DNA double-stranded breaks (Fig. 4A and B). To further confirm the changes in chromatin structure in irradiation-induced senescent cells, senescence-associated heterochromatic foci (SAHF) formation in nuclei was assessed and visualized using DAPI staining (Fig. 4C and D), which exhibited nucleolus enlargement, and significant loss and compromised nuclear integrity indicative of nuclear chromatin structure injury, and the effects were dose-dependent. The expression of SA- $\beta$-gal, a marker product of senescent cells, was increased in a dose-dependent manner (Fig. 5A and B). Additionally, for further identification of osteocyte senescence induced by irradiation, upregulation of 

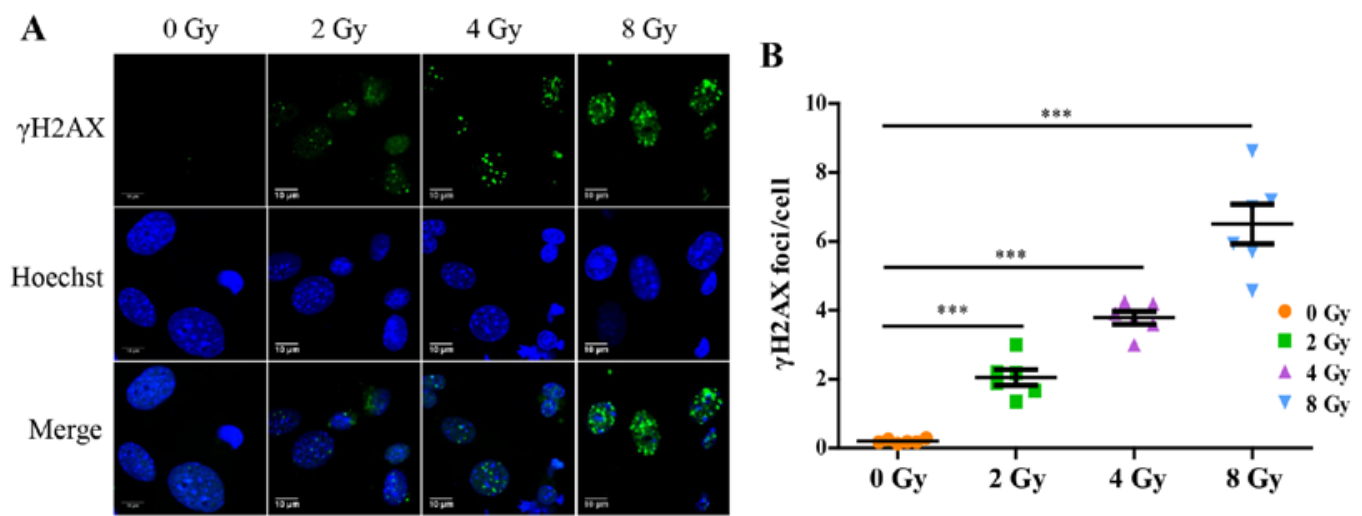

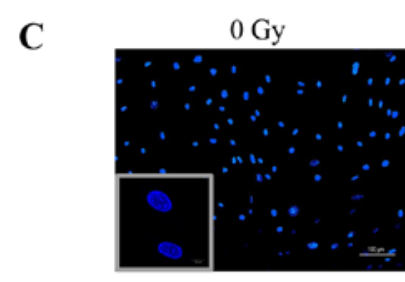

4 Gy

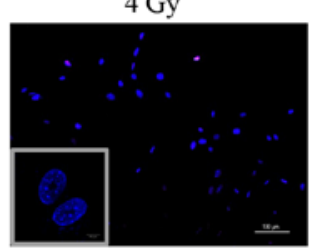

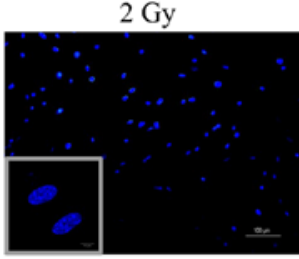

$8 \mathrm{~Gy}$

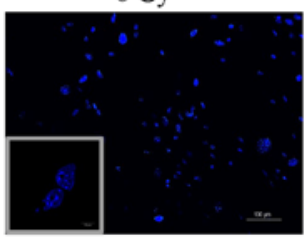

\section{D}

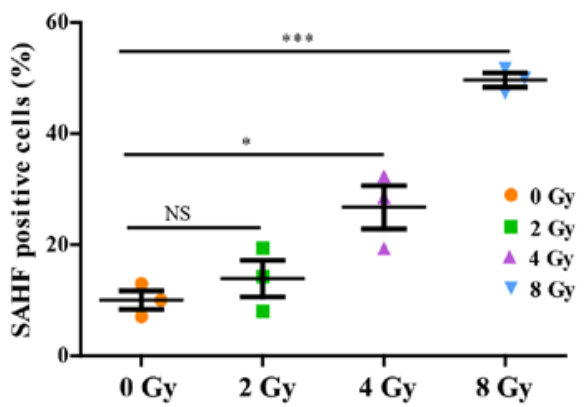

Figure 4. Irradiation results in DNA damage and the development of SAHF in primary osteocytes. (A) Immunofluorescence staining of $\gamma \mathrm{H} 2 \mathrm{AX}$ in osteocytes $7 \mathrm{~h}$ post irradiation. Scale bar, $10 \mu \mathrm{m}$. (B) Quantitative analysis of $\gamma$-H2AX foci per cell. $\mathrm{n}=6$. (C) SAHF formation was observed using confocal microscopy 3 days after irradiation, and was characterized by punctate DNA foci in irradiated-osteocyte nuclei. Scale bar, $10 \mu \mathrm{m}$. (D) Quantification of SAHF positive cells from three random fields of view. Data are presented as the mean \pm standard deviation. NS, not significant, ${ }^{*} \mathrm{P}<0.05,{ }^{* * * *} \mathrm{P}<0.001$ vs. 0 Gy. SAHF, senescence-associated heterochromatic foci.
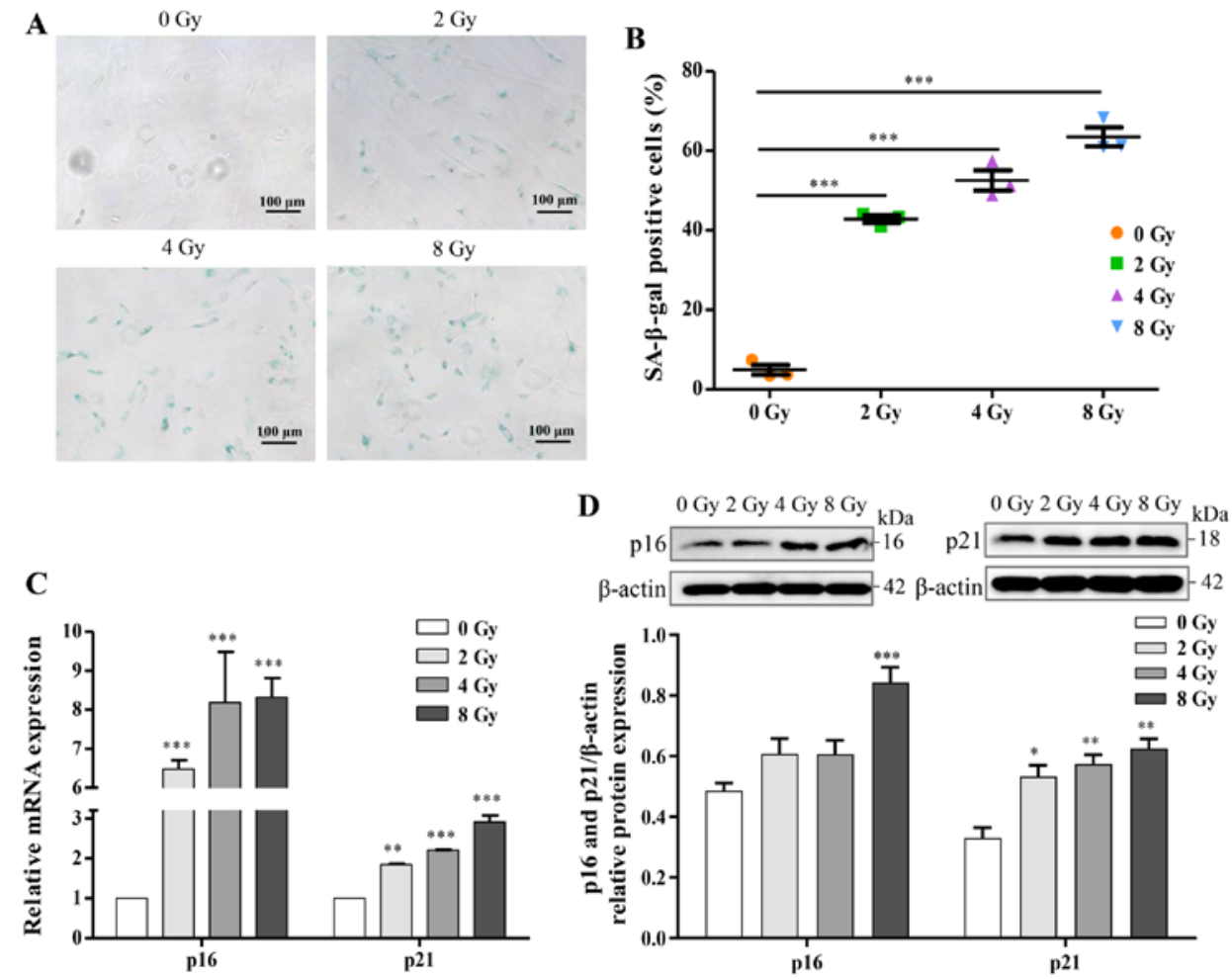

Figure 5. Irradiation initiates cellular senescence in primary osteocytes. (A and B) SA- $\beta$-gal staining in osteocytes 5 days post-irradiation and quantification of SA- $\beta$-gal-positive osteocytes. Scale bar, $100 \mu \mathrm{m}$. (C) Relative mRNA expression of p16 and p21 in irradiated osteocytes was detected (n=3). (D) Protein expression levels of p16 and p21 in irradiated osteocytes $(\mathrm{n}=3)$. Data are presented as the mean \pm standard deviation. ${ }^{*} \mathrm{P}<0.05,{ }^{* * *} \mathrm{P}<0.01,{ }^{* * * *} \mathrm{P}<0.001 \mathrm{vs}$. control. SA- $\beta$-gal, senescence-associated $\beta$-galactosidase. 
A

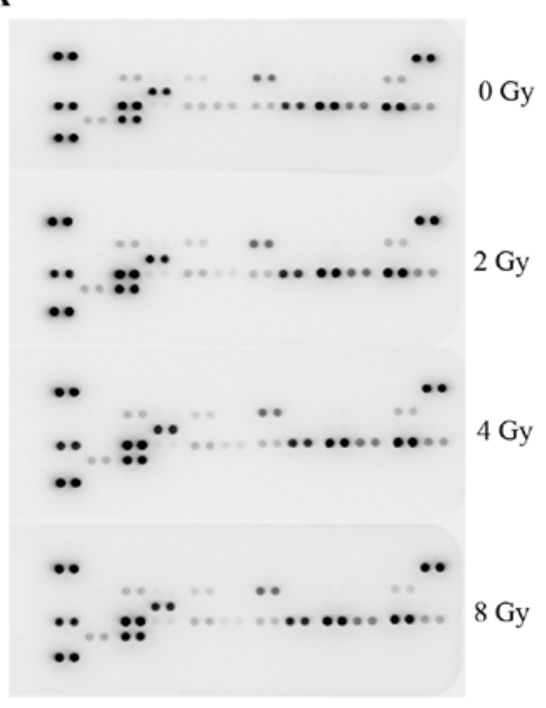

B

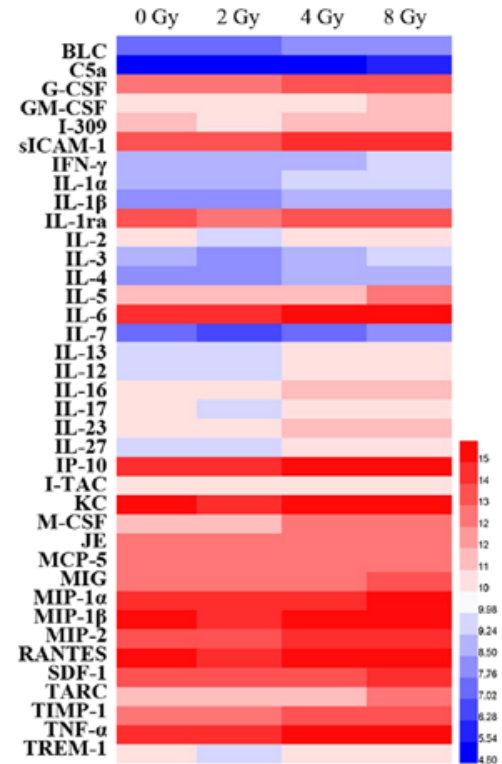

C
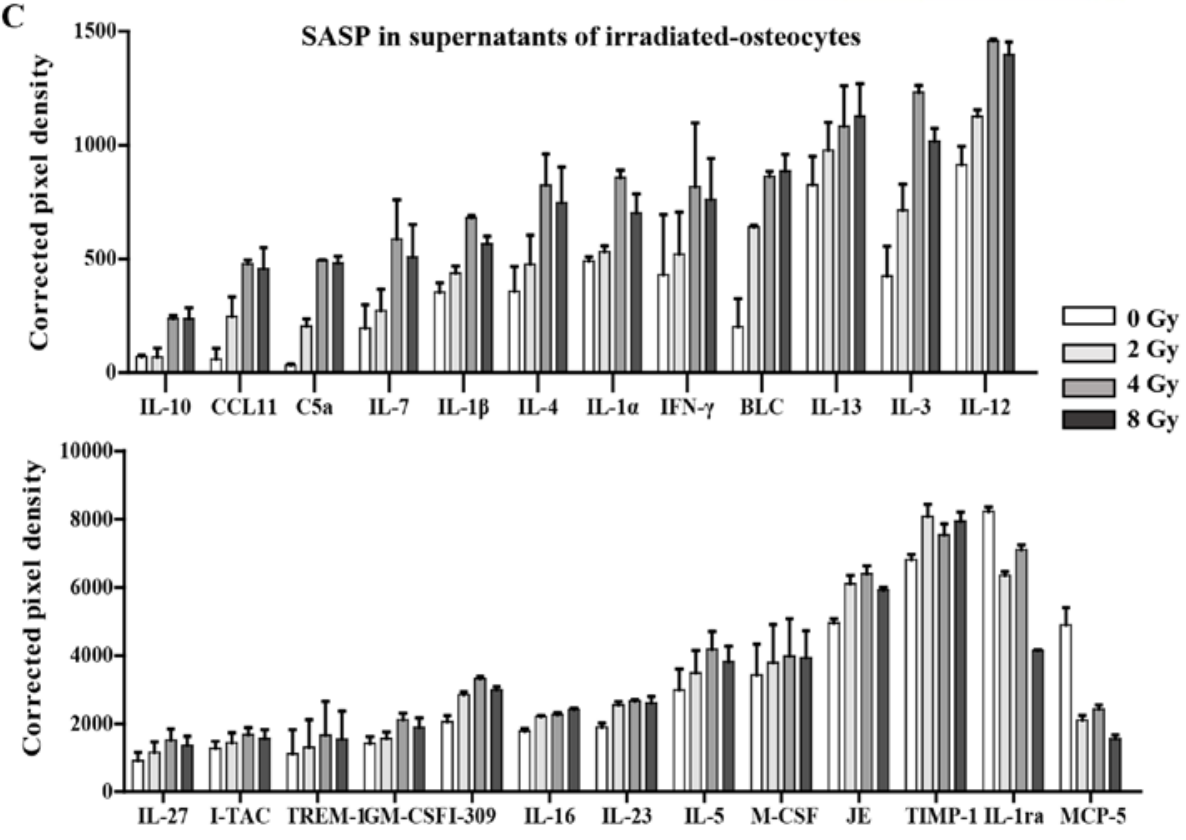

Figure 6. Prematurely senescent osteocytes induced by irradiation secrete multiple SASP components in a dose-depended manner. (A) Levels of soluble SASP components in the CS of irradiated osteocytes at third day after exposure were detected using Mouse Cytokine Array membrane analysis (n=2). (B) Heat map representation of secreted cytokines. (C) Expression levels of the indicated secretory cytokines and chemokines were quantified and presented as the corrected pixel density $(n=2)$. Bar graphs show the mean intensity of the developed spots \pm standard deviation. Results are presented as mean \pm standard deviation. SASP, senescence-associated secretory phenotype; CS, culture supernatants.

aging-pathway proteins, p16 and p21, were assayed by western blotting and RT-qPCR analysis, and the results were consistent with cellular senescence (Fig. 5C and D). Taken together, the results suggested that irradiation induced DNA damage and may thus stimulate cellular senescence in primary osteocytes.

Irradiation induces prematurely senescent osteocytes and regulates osteoclastogenesis via a paracrine pathway. Accumulating evidence has suggested that SASP production is typically a consequence of activated downstream pathways of senescence, and it serves a pivotal role in specific pathologies of aging diseases $(36,37)$. However, the underlying mechanism of the senescent phenotype in the premature aging of irradiation-induced cells in the bone microenvironment, particularly for osteocytes, is still incompletely understood.
Thus, in the present study the SASP factors from osteocyte culture supernatants were investigated using a Mouse Cytokine Array panel (Fig. 6A). The analysis showed that the release of 23 cytokines associated with SASP were significantly increased in supernatants from radiation-induced senescent osteocytes, including pro-inflammatory interleukin family members (IL-4, IL-7 and IL-3), chemokines (CCL11 and I-309), interferon- $\gamma$, and various other cytokines. Interestingly, certain cytokines, such as IL-1ra and MCP-5, were downregulated following irradiation (Fig. 6B and C). Expression of several chemokines were not significantly altered and are thus not listed. Additionally, RT-qPCR analysis further confirmed that irradiation-induced prematurely senescent osteocytes could activate multiple SASP components, including NF- $\kappa$ B, TNF- $\alpha$, MMP13, IL-1 $\alpha$ and IL-6 (Fig. 7A), all of which are 
A

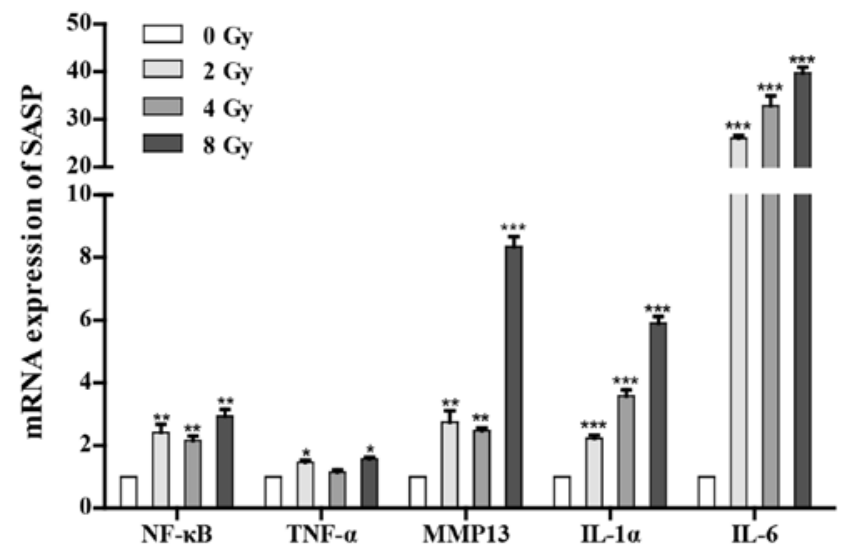

B $\quad+0$ Gy-OCY
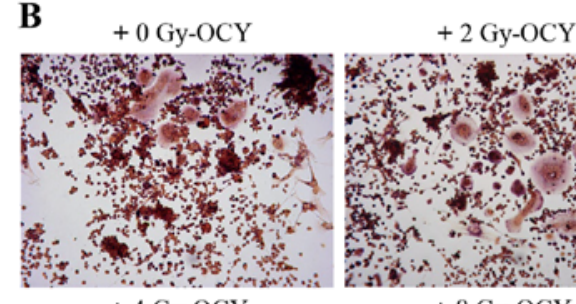

$+4 \mathrm{~Gy}-\mathrm{OCY}$
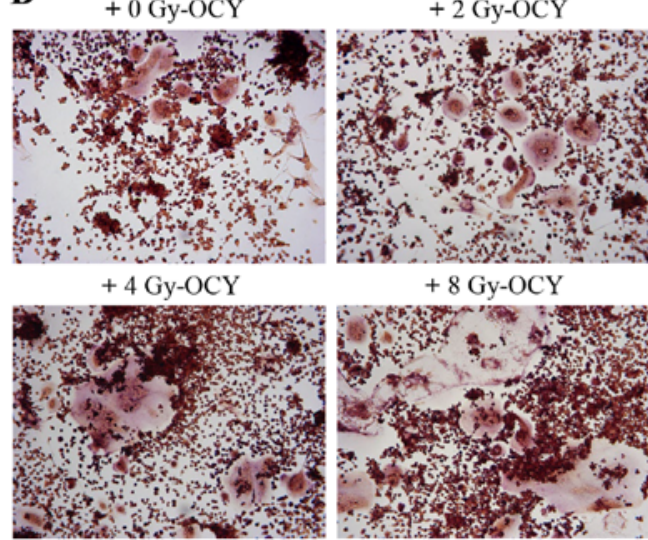
$+8 \mathrm{~Gy}-\mathrm{OCY}$

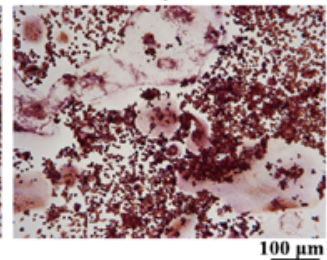

$\mathrm{C}$

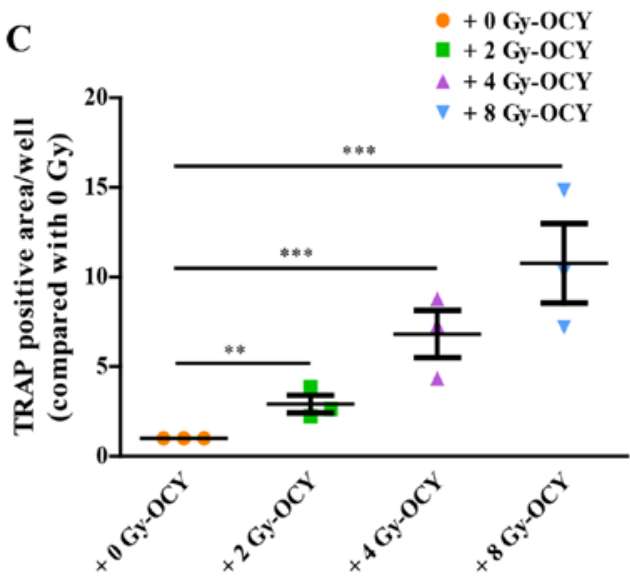

Figure 7. SASP from irradiation-induced prematurely senescent osteocytes participate in unbalancing the homeostasis of osteoclastogenesis. (A) mRNA expression levels of several SASP components from radiation-induced senescent osteocytes ( $n=3$ ). (B) TRAP staining of RAW264.7 cells co-cultured with OCY for 7 days with RANKL stimulation. Scale bar, $100 \mu \mathrm{m}$. Magnification, x100. (C) TRAP positive area was calculated in OCY co-cultured with RAW264.7 cells $(n=3)$. Results are presented as the mean \pm standard deviation. ${ }^{*} \mathrm{P}<0.05,{ }^{* *} \mathrm{P}<0.01,{ }^{* * *} \mathrm{P}<0.001$ vs. 0 Gy. SASP, senescence-associated secretory phenotype; TRAP, tartrate-resistant acid phosphatase; OCY, irradiated-osteocytes.

associated with bone metabolism (38-41). These results suggest that radiation-induced prematurely senescent osteocytes may produce and secrete SASP components, which in turn may regulate other cells in the surrounding medium, and may also activate macrophages.

Osteocytes, embedded within the bone matrix, are considered a type of endocrine cell which function to orchestrate the bone microenvironment via secretion of functional proteins targeting osteoclasts and osteoblasts $(12,17,42)$. Significant induction of SASP components in irradiated osteocytes emphasizes their potential role in radiation-induced bone imbalances in remodeling. Subsequently, the effects of SASP-mediated osteoclastogenesis, which depends on activation of bone marrow macrophages, were characterized. As an osteoclast precursor cell line, RAW264.7 cells, a commonly used bone marrow macrophage cell line, were co-cultured with osteocytes previously irradiated with 2,4 or 8 Gy $\gamma$-rays, and treated with $25 \mathrm{ng} / \mathrm{ml}$ RANKL in order to observe their osteoclastogenesis potential. The results showed that compared with the non-irradiated osteocyte co-culture, irradiated osteocytes significantly promoted the differentiation of osteoclast precursors as evidenced by TRAP staining (Fig. 7B and C), in a dose-dependent manner. Together, these results suggest that the secretion of SASP components is influenced by irradiation, and thus, at least in part, mediate osteoclastogenesis imbalances in the bone microenvironment.

\section{Discussion}

Previous studies investigating radiation-induced bone loss have primarily focused on either the activation of osteoblasts or the inhibition of osteoclasts $(7,43)$. However, changes in osteocyte function and molecular communication in response to irradiation have not been assessed, to the best of our knowledge. Osteocytes are abundantly present within the bone matrix and orchestrate both osteoblasts and osteoclasts; osteocytes were previously obtained from the long bones through a process of collagenase digestions combined with EDTA-based multiple decalcifications $(28,29,44)$. The above sequential digestion method was unsuitable for cellular research due to the time-consuming nature, therefore murine osteocyte cell lines such as MLO-Y4 have been almost exclusively used in in vitro studies of osteocytes $(45,46)$. In the present study, an optimized method based on these protocols was used to obtain primary osteocytes from the long bone tissue, and then subcultured. Subsequently, the identity of the obtained cells was further confirmed based on a lack of ALP staining and the analysis of protein marker expression. Osteocyte was traditionally viewed as a descendant of osteoblast (34). Previous research has indicated that with the transition process from osteoblasts to osteocytes, alkaline phosphatase is remarkably reduced, so that osteocytes showed negative or only weakly positive for ALP expression which was different from osteoblasts (30). In 
addition, during the isolation of osteocytes, a small number of osteoblasts are still inevitably mixed into the osteocytes population. Considering these factual evidences, the presence of ALP in Fig. 1B is caused by either contaminating osteoblasts or weakly-expressed osteocytes. However, compared with the strong expression of osteoblasts in Fig. 1B, identification of osteocytes and effectiveness for isolation remain to be elucidated. Overall, a detailed methodology was adapted to enable the isolation and identification of primary osteocytes from mice skeletal tissue. This novel primary osteocyte model possesses several advantages over cell lines and may assist in improving our understanding of the roles of mature osteocytes in skeletal homeostasis and remodeling.

Concerning the direct damage of irradiation to biological function in osteocytes, irradiation can markedly inhibit the viability and proliferation of osteocytes, which ultimately leads to a decreased number of osteocytes in a dose-dependent manner. Although a high dose of radiation tends to induce more apoptosis and necrosis, previous research had demonstrated that the initial apoptotic cells tend to die rapidly, and the majority of surviving cells maintain senescence (46-48). Given these evidences, at 5 days after radiation a small number of apoptosis or necrosis osteocytes were inevitably mixed into exiting populations, while the majority of surviving cells maintain senescence. Additionally, it was shown that irradiated primary osteocytes presented obvious morphological changes, including sparsely distributed cells, shortened or disappeared dendritic branches and disordered cytoskeleton, which were consistent with reduced mRNA and protein expression levels of E11, leading to the dysfunction of direct communication between embedded osteocytes and the surrounding cells. Accordingly, this study also demonstrated that irradiation upregulated the expression of SOST and RANKL, whereas OPG expression was decreased. In conclusion, the above results reflect the functional damage of osteocytes by irradiation in the modulatory process of bone homeostasis.

Furthermore, increasing in vitro and in vivo evidence has shown that bone loss is a normal consequence associated with aging (49,50). More recently, several molecular mechanisms, including oxidative stress and DNA damage have been observed to be increased in senescence and irradiation (21). Interestingly, the present study demonstrated that irradiated osteocytes showed several markers associated with DNA damage and cellular senescence, including the elevated accumulation of $\gamma \mathrm{H} 2 \mathrm{AX}$, positive SA- $\beta$-gal staining, and upregulated expression of p16 and p21 at both the mRNA and protein level, as well as a novel SAHF indicator. These results suggested that irradiation, as an alternative promoter of oxidative stress and DNA damage, may also initiate cellular senescence of osteocytes in vitro. Moreover, the methods used in the present study may improve the identification of senescence, and allow for easier differentiation between stimulator-induced premature senescence compared with age-related natural aging.

It was previously reported that SASP triggers senescence of the surrounding normal cells $(51,52)$. Many studies have focused on these secreted factors and their proposed mechanism in bone metabolism $(12,53)$. IL-17A was found to mediate the promotion of osteoclastogenesis by osteocyte paracrine pathways (54), and MCP-1 has been indicated to play an important role in bone remodelling and bone-related cancers (55). Additionally, drug intervention targeting the SASP profile may be a hopeful approach that can potentially improve bone integrity and function $(19,50,56)$. For example, it was confirmed that inhibition of $\mathrm{C} 5 \mathrm{a} / \mathrm{C} 5 \mathrm{aR}$ axis could alleviate osteoclast degradation (57). In the current study, we indicated that besides the direct dysfunctional damage, osteocytes undergoing irradiation-induced senescence may significantly increase the expression and secretion of SASP in the surrounding environment. Following co-culture, irradiated osteocytes promoted the differentiation of nearby RAW264.7 cells, highlighting the paracrine effects of senescent osteocytes in co-ordinating other cell activities in the bone microenvironment. These results suggest that senescent osteocytes modulate bone remodeling via a paracrine pathway targeting the associated bone-metabolizing cells. A recent study demonstrated that targeted reduction of senescent cells could alleviate focal radiotherapy-related bone loss (27), consistent with the results of the present study, and this may partially be explained by the possible cellular senescence mechanism. Taken together, these results suggest that the accumulation of senescent osteocytes and increased SASP secretion induced by radiation are likely one of the primary initiators of bone damage, or even increased risk of bone metastasis in post-radiotherapy cancer patients.

Collectively, these results suggested that irradiation decreased cell viability and disrupted fundamental biological functions of osteocytes, as well as altered the crucial dendritic morphology and the regulatory function via changes in the expression levels of E11, RANKL, OPG and SOST. Additionally, it was shown that irradiation resulted in the accumulation of DNA damage and thereby initiated senescence in osteocytes. Furthermore, irradiation induced prematurely senescent osteocytes to obtain a SASP, which in turn, indirectly participated in osteoclastogenesis imbalance. The paracrine modulatory process of osteocytes was also involved in a series of molecular mechanisms. However, it remains to be determined which specific upstream and downstream responses SASP and senescent osteocytes modulate to exhibit their effects in radiation-induced bone loss.

In conclusion, the present study provides insights into the mechanisms underlying irradiation-induced bone loss by showing that irradiated osteocytes prematurely senescent damage and SASP secretion serve as crucial regulators of bone metabolism.

\section{Acknowledgements}

Not applicable.

\section{Funding}

This study was funded by Shanghai Municipal Health Commission under contract number GWV-10.1-XK10.

\section{Availability of data and materials}

The datasets generated and/or analyzed in the present study are all included in this published article. 


\section{Authors' contributions}

GZ designed the study and revised the article. YW and JW performed the experiments. JB, LX and JZ analyzed the data. YW wrote the manuscript. All authors have read and approved the final manuscript.

\section{Ethics approval and consent to participate}

All the animal experimental procedures were approved by the Committee for Ethical Use of Experimental Animal at Fudan University (approval no. 201703FYSZGY01).

\section{Patient consent for publication}

Not applicable.

\section{Competing interests}

The authors declare that they have no competing interests.

\section{References}

1. Allen C, Her S and Jaffray DA: Radiotherapy for cancer: Present and future. Adv Drug Deliv Rev 109: 1-2, 2017.

2. Mendes EM, Irie MS, Rabelo GD, Borges JS, Dechichi P, Diniz RS and Soares PBF: Effects of ionizing radiation on woven bone: Influence on the osteocyte lacunar network, collagen maturation, and microarchitecture. Clin Oral Investig 24: 2763-2771, 2020.

3. Schmeler KM, Jhingran A, Iyer RB, Sun CC, Eifel PJ, Soliman PT, Ramirez PT, Frumovitz M, Bodurka DC and Sood AK: Pelvic fractures after radiotherapy for cervical cancer: Implications for survivors. Cancer 116: 625-630, 2010.

4. Zhang J, Qiu X, Xi K, Hu W, Pei H, Nie J, Wang Z, Ding J, Shang P, Li B and Zhou G: Therapeutic ionizing radiation induced bone loss: A review of in vivo and in vitro findings. Connect Tissue Res 59: 509-522, 2018.

5. Saintigny Y, Cruet-Hennequart S, Hamdi DH, Chevalier F and Lefaix JL: Impact of therapeutic irradiation on healthy articular cartilage. Radiat Res 183: 135-146, 2015.

6. Alwood JS, Shahnazari M, Chicana B, Schreurs AS, Kumar A Bartolini A, Shirazi-Fard Y and Globus RK: Ionizing radiation stimulates expression of pro-osteoclastogenic genes in marrow and skeletal tissue. J Interferon Cytokine Res 35: 480-487, 2015

7. Jia D, Gaddy D, Suva LJ and Corry PM: Rapid loss of bone mass and strength in mice after abdominal irradiation. Radiat Res 176 624-635, 2011

8. Bonewald LF: The role of the osteocyte in bone and nonbone disease. Endocrinol Metab Clin North Am 46: 1-18, 2017.

9. Dallas SL, Prideaux M and Bonewald LF: The osteocyte: An endocrine cell ... and more. Endocr Rev 34: 658-690, 2013.

10. Klein-Nulend J, Bakker AD, Bacabac RG, Vatsa A and Weinbaum S: Mechanosensation and transduction in osteocytes. Bone 54: 182-190, 2013.

11. Robling AG and Bonewald LF: The osteocyte: New insights. Annu Rev Physiol 82: 485-506, 2020.

12. Kitaura H, Marahleh A, Ohori F, Noguchi T, Shen WR, Qi J, Nara Y,Pramusita A, Kinjo R and Mizoguchi I: Osteocyte-related cytokines regulate osteoclast formation and bone resorption. Int J Mol Sci 21: 5169, 2020

13. Staines KA, Javaheri B, Hohenstein P, Fleming R, Ikpegbu E, Unger E, Hopkinson M, Buttle DJ, Pitsillides AA and Farquharson C: Hypomorphic conditional deletion of E11/Podoplanin reveals a role in osteocyte dendrite elongation. J Cell Physiol 232: 3006-3019, 2017.

14. Bellido T: Osteocyte-driven bone remodeling. Calcif Tissue Int 94: 25-34, 2014

15. Staines KA, Hopkinson M, Dillon S, Stephen LA, Fleming R, Sophocleous A, Buttle DJ, Pitsillides AA and Farquharson C: Conditional deletion of E11/Podoplanin in bone protects agains ovariectomy-induced increases in osteoclast formation and activity. Biosci Rep 40: BSR20190329, 2020
16. Bonewald LF: The amazing osteocyte. J Bone Miner Res 26 229-238, 2011.

17. Honma M, Ikebuchi Y, Kariya Y, Hayashi M, Hayashi N, Aoki S and Suzuki H: RANKL subcellular trafficking and regulatory mechanisms in osteocytes. J Bone Miner Res 28: 1936-1949, 2013

18. Mas-Bargues C, Viña-Almunia J, Inglés M, Sanz-Ros J, Gambini J, Ibáñez-Cabellos JS, García-Giménez JL, Viña J and Borrás C: Role of $\mathrm{p}^{16^{\mathrm{INK}} 4 \mathrm{a}}$ and BMI-1 in oxidative stress-induced premature senescence in human dental pulp stem cells. Redox Biol 12: 690-698, 2017.

19. Pignolo RJ, Samsonraj RM, Law SF, Wang H and Chandra A: Targeting cell senescence for the treatment of age-related bone loss. Curr Osteoporos Rep 17: 70-85, 2019.

20. Dou Z, Ghosh K, Vizioli MG, Zhu J, Sen P, Wangensteen KJ, Simithy J, Lan Y, Lin Y, Zhou Z, et al: Cytoplasmic chromatin triggers inflammation in senescence and cancer. Nature 550: 402-406, 2017.

21. Chandra A, Park SS and Pignolo RJ: Potential role of senescence in radiation-induced damage of the aged skeleton. Bone 120 423-431, 2019.

22. Cmielova J, Havelek R, Soukup T, Jiroutová A, Visek B, Suchánek J, Vavrova J, Mokry J, Muthna D, Bruckova L, et al: Gamma radiation induces senescence in human adult mesenchymal stem cells from bone marrow and periodontal ligaments. Int J Radiat Biol 88: 393-404, 2012.

23. Bai J, Wang Y, Wang J,Zhai J,He Fand Zhu G: Irradiation-induced senescence of bone marrow mesenchymal stem cells aggravates osteogenic differentiation dysfunction via paracrine signaling. Am J Physiol Cell Physiol 318: C1005-C1017, 2020.

24. Sapieha P and Mallette FA: Cellular senescence in postmitotic cells: Beyond growth arrest. Trends Cell Biol 28: 595-607, 2018.

25. Anderson R, Lagnado A, Maggiorani D, Walaszczyk A, Dookun E, Chapman J, Birch J, Salmonowicz H, Ogrodnik M, Jurk D, et al: Length-independent telomere damage drives post-mitotic cardiomyocyte senescence. EMBO J 38: e100492, 2019.

26. Riessland M, Kolisnyk B, Kim TW, Cheng J, Ni J, Pearson JA, Park EJ, Dam K, Acehan D, Ramos-Espiritu LS, et al: Loss of SATB1 induces p21-dependent cellular senescence in post-mitotic dopaminergic neurons. Cell Stem Cell 25: 514-530.e8, 2019.

27. Gu G, Nars M, Hentunen TA, Metsikkö $K$ and Väänänen $H K$ : Isolated primary osteocytes express functional gap junctions in vitro. Cell Tissue Res 323: 263-271, 2006.

28. Stern AR, Stern MM, Van Dyke ME, Jähn K, Prideaux M and Bonewald LF: Isolation and culture of primary osteocytes from the long bones of skeletally mature and aged mice. Biotechniques 52: 361-373, 2012.

29. Stern AR and Bonewald LF: Isolation of osteocytes from mature and aged murine bone. Methods Mol Biol 1226: 3-10, 2015

30. Franz-Odendaal TA, Hall BK and Witten PE: Buried alive: How osteoblasts become osteocytes. Dev Dyn 235: 176-190, 2006.

31. Fartaria MJ, Reis C, Pereira J, Pereira MF, Cardoso JV, Santos LM, Oliveira C, Holovey V, Pascoal A and Alves JG: Assessment of the mean glandular dose using LiF:Mg,Ti, LiF:Mg,Cu,P, Li2B4O7:Mn and Li2B4O7:Cu TL detectors in mammography radiation fields. Phys Med Biol 61: 6384-6399, 2016.

32. Lucas PA, Aubineau-Lanièce I, Lourenço V, Vermesse D and Cutarella D: Using LiF:Mg,Cu,P TLDs to estimate the absorbed dose to water in liquid water around an 192Ir brachytherapy source. Med Phys 41: 011711, 2014.

33. Livak KJ and Schmittgen TD: Analysis of relative gene expression data using real-time quantitative PCR and the 2(-Delta Delta $\mathrm{C}(\mathrm{T})$ ) method. Methods 25: 402-408, 2001

34. Manolagas SC: Birth and death of bone cells: Basic regulatory mechanisms and implications for the pathogenesis and treatment of osteoporosis. Endocr Rev 21: 115-137, 2000.

35. Ikpegbu E, Basta L, Clements DN, Fleming R, Vincent TL, Buttle DJ, Pitsillides AA, Staines KA and Farquharson C: FGF-2 promotes osteocyte differentiation through increased E11/podoplanin expression. J Cell Physiol 233: 5334-5347, 2018.

36. Childs BG, Durik M, Baker DJ and van Deursen JM: Cellular senescence in aging and age-related disease: From mechanisms to therapy. Nat Med 21: 1424-1435, 2015.

37. Childs BG, Gluscevic M, Baker DJ, Laberge RM, Marquess D, Dananberg J and van Deursen JM: Senescent cells: An emerging target for diseases of ageing. Nat Rev Drug Discov 16: 718-735, 2017.

38. Zhang Y, Huang H, Zhao G, Yokoyama T, Vega H, Huang Y, Sood R, Bishop K, Maduro V, Accardi J, et al: ATP6V1H deficiency impairs bone development through activation of MMP9 and MMP13. PLoS Genet 13: e1006481, 2017. 
39. Hameister R, Lohmann CH, Dheen ST, Singh G and Kaur C: The effect of TNF- $\alpha$ on osteoblasts in metal wear-induced periprosthetic bone loss. Bone Joint Res 9: 827-839, 2020.

40. Dinarello CA: The IL-1 family of cytokines and receptors in rheumatic diseases. Nat Rev Rheumatol 15: 612-632, 2019.

41. Kim MH, Lee H, Ha IJ and Yang WM: Zanthoxylum piperitum alleviates the bone loss in osteoporosis via inhibition of RANKL-induced c-fos/NFATc $1 / \mathrm{NF}-\kappa \mathrm{B}$ pathway. Phytomedicine 80: 153397, 2021.

42. Maré A, D'Haese PC and Verhulst A: The role of sclerostin in bone and ectopic calcification. Int J Mol Sci 21: 3199, 2020.

43. Zhang J, Wang Z, Wu A, Nie J, Pei H, Hu W, Wang B, Shang P, Li B and Zhou G: Differences in responses to X-ray exposure between osteoclast and osteoblast cells. J Radiat Res 58: 791-802, 2017.

44. Metzger CE and Narayanan SA: The role of osteocytes in inflammatory bone loss. Front Endocrinol (Lausanne) 10: 285, 2019.

45. Bonewald LF: Establishment and characterization of an osteocyte-like cell line, MLO-Y4. J Bone Miner Metab 17: 61-65, 1999.

46. He F, Bai J, Wang J, Zhai J, Tong L and Zhu G: Irradiation-induced osteocyte damage promotes HMGB1-mediated osteoclastogenesis in vitro. J Cell Physiol 234: 17314-17325, 2019.

47. Alessio N, Esposito G, Galano G, De Rosa R, Anello P, Peluso G, Tabocchini MA and Galderisi U: Irradiation of mesenchymal stromal cells with low and high doses of alpha particles induces senescence and/or apoptosis. J Cell Biochem 118: 2993-3002, 2017.

48. Alessio N, Capasso S, Di Bernardo G, Cappabianca S, Casale F, Calarco A, Cipollaro M, Peluso G and Galderisi U: Mesenchymal stromal cells having inactivated RB1 survive following low irradiation and accumulate damaged DNA: Hints for side effects following radiotherapy. Cell Cycle 16: 251-258, 2017.

49. Tiede-Lewis LM, Xie Y, Hulbert MA, Campos R, Dallas MR, Dusevich V, Bonewald LF and Dallas SL: Degeneration of the osteocyte network in the C57BL/6 mouse model of aging. Aging (Albany NY) 9: 2190-2208, 2017.
50. Farr JN, Xu M, Weivoda MM, Monroe DG, Fraser DG, Onken JL Negley BA, Sfeir JG, Ogrodnik MB, Hachfeld CM, et al: Targeting cellular senescence prevents age-related bone loss in mice. Nat Med 23: 1072-1079, 2017.

51. Hitomi K, Okada R, Loo TM, Miyata K, Nakamura AJ and Takahashi A: DNA damage regulates senescence-associated extracellular vesicle release via the ceramide pathway to prevent excessive inflammatory responses. Int J Mol Sci 21: 3720, 2020.

52. Faget DV, Ren Q and Stewart SA: Unmasking senescence: Context-dependent effects of SASP in cancer. Nat Rev Cancer 19: 439-453, 2019.

53. Farr JN, Fraser DG, Wang H, Jaehn K, Ogrodnik MB, Weivoda MM, Drake MT, Tchkonia T, LeBrasseur NK, Kirkland JL, et al: Identification of senescent cells in the bone microenvironment. J Bone Miner Res 31: 1920-1929, 2016.

54. Liao C, Cheng T, Wang S, Zhang C, Jin L and Yang Y: Shear stress inhibits IL-17A-mediated induction of osteoclastogenesis via osteocyte pathways. Bone 101: 10-20, 2017.

55. Mulholland BS, Forwood MR and Morrison NA: Monocyte chemoattractant protein-1 (MCP-1/CCL2) drives activation of bone remodelling and skeletal metastasis. Curr Osteoporos Rep 17: 538-547, 2019.

56. Chandra A, Lagnado AB, Farr JN, Monroe DG, Park S, Hachfeld C, Tchkonia T, Kirkland JL, Khosla S, Passos JF and Pignolo RJ: Targeted reduction of senescent cell burden alleviates focal radiotherapy-related bone loss. J Bone Miner Res 35: 1119-1131, 2020.

57. D'Angelo R, Mangini M, Fonderico J, Fulle S, Mayo E, Aramini A and Mariggiò S: Inhibition of osteoclast activity by complement regulation with DF3016A, a novel small-molecular-weight C5aR inhibitor. Biomed Pharmacother 123: 109764, 2020.

This work is licensed under a Creative Commons Attribution-NonCommercial-NoDerivatives 4.0 International (CC BY-NC-ND 4.0) License. 